\title{
Prevalence of Anemia and Risk Factors Among Pregnant Mothers Attending Antenatal Care at Jimma University Specialized Hospital, South-West Ethiopia
}

\author{
Masresha Assefa Demissie ${ }^{1^{*}} \quad$ Abdulfetah Sirmolo ${ }^{2}$ \\ 1.Department of Neonatology and Paediatrics Nursing, College of Health Science and Medicine, Wolaita Sodo \\ University, Wolaita Sodo, Ethiopia \\ 2.Department of Public Health, College of Health Science and Medicine, Jimma University, Jimma, Ethiopia
}

\begin{abstract}
Background: Anemia is one of the most frequently observed nutritional deficiency diseases in the world today .It is especially prevalent in the women of reproductive age , particularly during pregnancy when it is contributing for maternal death. The diagnosis is made by clinical examination and investigation for hemoglobin or Hematocrite level .Depending on the hemoglobin level, anemia categorized as moderate and severe which is important for management. Objective: The main objective of this study was to determine the prevalence of anemia and associated risk factors among pregnant women attending antenatal care clinic at Jimma University Specialized Hospital from February to June, 2018 Methods: institutional based cross-sectional study was employed to assess the presence of anemia in all pregnant women attending antenatal care clinic of Jimma University Specialized Hospital. Finally collected data was analyzed by using SPSS. Depending on the clinical manifestation, assessing associated factors, laboratory determination of hemoglobin level and stool examination, the result were summarized by using tables and chi-square. Results: A total of 207 mothers were seen during the study period with $100 \%$ response rate Among the study population65(31.4\%) had anemia with a mean hemoglobin level of $11.4 \mathrm{gm} / \mathrm{dl}$ and $9.6 \mathrm{gm} / \mathrm{dl}$ for the total and anemic mothers respectively Regarding age $105(50.7 \%)$ of the study population were in the age group of $18-25,88(42.5 \%)$ were in the age group of $26-35$ and $7(3.4 \%)$ of the study population were in the age group of $<18$ year and $>35$ years. $124(59.9 \%)$ of the study population were living in urban, $40.6 \%$ of the of the study population had attended secondary school and above. Anemia had a significant association $(\mathrm{P}<0.05)$ with hook worm infestation, chronic illness, parity and age of pregnant mothers. Conclusion: the result of this study showed that the occurrence of anemia in pregnancy has been present in large population of pregnant women. The rate of anemia being higher among grand multiparas, in third trimester of pregnancy and age more than 35 years and in mothers who had chronic illnesses. Key words: Anemia, pregnant, ANC, JUSH
\end{abstract}

DOI: $10.7176 / \mathrm{JHMN} / 65-04$

Publication date: August $31^{\text {st }} 2019$

\section{Introduction}

Anemia in pregnancy is defined when the distribution of hemoglobin $(\mathrm{Hgb})$ level is below the fifth percentile. The cut off value varies by trimesters of pregnancy. Anemia is said to be present if $\mathrm{Hgb}$ level is less than $11 \mathrm{gm} / \mathrm{dl}$ or hematocrite (Hct) is $<33 \%$ in the first trimester and third trimester, and less than $10.5 \mathrm{gm} / \mathrm{dl}(\mathrm{HCt}<32 \%)$ in the second trimester.

Maternal Hgb below $6 \mathrm{gm} / \mathrm{dl}$ has been associated with reduced amniotic fluid volume, fetal cerebral vasodilatation and non re assuring fetal heart rate patterns. Increased risk of prematurity, Spontaneous abortion, LBW, and fetal death has also been reported. In addition, severe anemia $(\mathrm{Hgb}<7 \mathrm{gm} / \mathrm{dl})$ increases the risk of maternal mortality (1).

Anemia is one of the major public health problems affecting all ages of population with its highest prevalence among under five year of age and pregnant women. Globally anemia affect 1.62 billion people (25\%), among which 56 million are pregnant women $(2,3)$.

Globally anemia contributes to $20 \%$ of all maternal death and it is one of the most intractable public health problem in developing countries $(3,4)$. Anemia in pregnancy is a major health problem in tropical countries, because it is extremely common and is strongly associated with maternal and fetal morbidity and mortality. Severe anemia can lead to cardiac failure in pregnancy, while lesser grades of severity are associated with decreased maternal well-being and contributes to maternal death from the hemorrhage or infection. Anemia also contributes to prenatal morbidity and mortality by increasing the likelihood of intrauterine growth retardation or preterm delivery (5).

Ethiopia is one of the countries where there is high level of anemia among women of reproductive age (1549) and pregnant women. According to the 2011 Ethiopian Demographic and Health Survey (EDHS) $17 \%$ Of Ethiopian women age 15-49 are anemic, with $13 \%$ have mild anemia, $3 \%$ having moderate anemia\& $1 \%$ have severe anemia(6)

The main risk factors for anemia are low intake of iron contain foods, poor absorption of iron from diet, 
increase requirement of iron and foliate during pregnancy, as well as infections like malaria, HIV and hook worm $(7,8)$. In light of this deficit the need of conducting this study is to determine the prevalence of anemia in women following antenatal care (ANC) and to identify the major associated factors, which potentially place pregnant women at high risk of acquiring anemia.

\section{Methods and materials}

Study area and period

The study was conducted in JUSH which is located at Jimma town. Jimma town is located in Oromia region, 346 $\mathrm{km}$ south west of the capital city of Ethiopia, Addis Ababa. JUSH is a teaching hospital and it is the only referral hospital in the south-western region of the country. The hospitals have four major, minor departments and follow up clinics. The gynecological and obstetrics department is one of the major departments in JUSH which has gynecology ward, maternity ward and labor ward. It also has two OPDs, one gynecology OPD and MCH clinic. Pregnant women are follows $\mathrm{ANC}$ follow up at $\mathrm{MCH}$ clinic.

$\mathrm{MCH}$ clinic gives different services like screening of anemia and nutritional status. It also gives therapeutic and preventive iron sulphate and foliate for pregnant women. The data collection was carried out from April 1530, 2018 G.C.

\section{Study Design}

Institutional based cross-sectional study was conducted among pregnant mothers attending antenatal care clinic of Jimma University specialized hospital.

\section{Study Participants}

Source population: All pregnant women attending antenatal care clinic in Jimma University Specialized Hospital. Study population: All clinically anemic pregnant women attending antenatal clinic during data collection period of Jimma University Specialized Hospital.

\section{Sample size and sampling technique}

The Sample size was calculated by using single population proportion formulas as follows:$\mathrm{ni}=(\mathrm{Z} \mathrm{\alpha /2})^{2} \mathrm{P}(1-\mathrm{p}) / \mathrm{d}^{2}$ by using $29 \%$ prevalence of anemia $(9), 95 \%$ confidence interval,5\% margin of error and $10 \%$ non-response rate the final sample size was 207 .

\section{Sampling technique}

Convenience sampling technique of every pregnant women attending $\mathrm{MCH}$ clinic during the period was used.

\section{Data collection instruments and technique}

Data were collected through face-to-face interview using pre-tested structured questionnaire. Physical examination and laboratory investigation were done. The hemoglobin level was determined by using CBC machine. Laboratory results were collected and registered properly. The external consistency was checked with different experts.

\section{Data Analysis:}

After data collection, Data were first checked manually for completeness and then coded and entered in to EpiData version 3.1. The entered data were transferred to SPSS version 20 for further processing. The data were cleaned by visualizing, calculating frequencies and sorting. The data were analyzed by using SPSS version 20 statistical software. Frequencies and proportions were computed for description of the study population in relation to relevant variables

Data quality assurance: To assure the quality of data properly, designed data collection tools were prepared before beginning of the actual data collection process. the questionnaire were translated to local language(Afan Oromo and Amharic) and then back to English to evaluate the correctness of the translation by expert who can speak both languages fluently. The questionnaire were pretested and the aim was to determine if any problem and difficulty in responding to the questions and check the questionnaire quality and if found to be corrected. Closed supervision was carried out by principal investigator.

\section{Ethical consideration}

Prior to data collection an official written letter from Jimma University was taken and submitted to the responsible hospital director. Subjects were informed about the objective of the study and verbal consent was made with the right not to participate in the study. Honesty and confidentiality were maintained throughout the study.

\section{Results}

A total of 207 mothers were seen during the study period with hundred percent response rates. Regarding age 
$105(50.7 \%)$ of the study population were in the age group of $18-25.88(42.5 \%)$ of study population were in age group of $26-35$ while $7(3.4 \%)$ and $7(3.4 \%)$ of the study population were in the age group of $<18$ and $>35$ respectively $.124(59.9 \%)$ of the study population were living in the urban area. The rest $83(40.1 \%)$ of the study population were living in rural area

Majority of attendants live in low socioeconomic status $(<1000)$ which is $157(76.8 \%)$ and only $4(1.9 \%)$ have economic status of more than 2000 birr per month. $91((44 \%)$ of attendants have children 1 and 2 but only 8(3.9\%) have children more than five.

From age $105(50.7 \%)$ of the study population were in the age group of $18-25$ of which $27(25.7 \%)$ of them were anemic $88(42.5 \%)$ of study population were in age group of $26-35$ while $32(36.3 \%)$ and $7(3.4 \%)$ of the study population were in the age group of $<18$ and $>35$ respectively $5(71.4 \%)$ were anemic in age group of $>35$ years $(\mathrm{p}=0.03)$

The prevalence of anemia increases with previous history of malarial attack compared with those having no attack of malaria. Out of 68 mothers who had malaria attack in the past 1 year,25( $36.8 \%$ )were anemic while out of 139 mothers who didn't have previous attack of malaria only $40(28.8 \%)$ were anemic. $(\mathrm{P}=0.024)$.

The occurrence of anemia increases with parity. $62.5 \%$ of grand multiparas in the study population were anemic while $47(34.5 \%)$ of mothers who were from Para I- IV were anemic and $62(30 \%)$ were primigravida of which $13(21 \%)$ were anemic. $(\mathrm{p}=0.032)$. $66 \%$ of mothers visited antenatal clinic in the second and third trimester of their pregnancy and $24 \%$ visited in their first trimester of pregnancy. The prevalence of anemia was $30.6 \%$ and $36 \%$ in the second and third trimester, respectively. $11(24 \%)$ of those in the first trimester were anemic. $(\mathrm{p}=0.345)$.

According to the World Bank classification of Growth National income all the mothers tested during the study period were in low socio economic status, out of these $159(76.8 \%$ )of the mothers have monthly income of $<1000$ birr) of which32.1\%were anemic. Only 4(1.9\%) have income $>2000$ birr. $105(50.7 \%)$ of the study population had history of contraceptive use out of which $27(25.7 \%)$ were anemic. $(p=0.071)$

Among the study population $31.4 \%$ had anemia with a mean hemoglobin level of $11.4 \mathrm{gm} / \mathrm{dl}$ and $9.6 \mathrm{gm} / \mathrm{dl}$ for the total and anemic mothers respectively. Out of the anemic mothers $25(46.6 \%)$ were found to have moderate anemia and 5(9.3\%) had severe anemia. The rate of anemia was $16.7 \%$ and $3.3 \%$ for the rural and urban, respectively.

\section{Discussion}

This study showed that the prevalence of anemia in pregnancy was $31.4 \%$ among the 207 attendant mothers. The prevalence was comparable with $27.2 \%$ study done in Tanzania (10). The prevalence was lower than previous study done at JUSH MCH clinic which was $38.2 \%$ (4). The reason may be in this study convenience sampling technique was used to select the attendants and they were tested at different visits. The prevalence of anemia in this study is higher than study done in Uganda (15.3\%). The difference may be attributed to advancements in the quality of ANC and living conditions in Uganda. (11).

High parity increases the risk of hemorrhage through intermediaries such as increased venous drainage to the lower part of uterus, hyalinization of the blood vessels and decreased elasticity of the uterine wall. (10) When these iron reserves are already low due to malnutrition, frequent pregnancies, malarial attack and hookworm, the severity of anemia is marked. High rates of anemia in pregnancy among primiparas were commonly found to be associated with adolescence and smoking. (11)

In one study done in university of Nigeria Teaching Hospital to determine the prevalence and risk factors for maternal anemia and the effect of HIV infection on severity of maternal anemia, the prevalence of overall anemia during pregnancy was $40.4 \%$. The majority $90.7 \%$ of these anemic women were mildly anemic $(\mathrm{Hgb}=9-10 \mathrm{gm} / \mathrm{dl})$ where as $9.3 \%$ were moderately anemic $(\mathrm{Hgb}=7-8.9 \mathrm{~g} / \mathrm{dl})$. The HIV status of 530 cases was done and 27 of the cases were positive for HIV infection out of which 20 (74\%) of mothers were anemic (12)

In this study, even though the serostats screening was not done, on historical background, 5 out of 207 mothers were positive for HIV. Out of these positive for HIV, $60 \%$ were anemic. The relative risk of sero positivity increased with severity of anemia, thus significant association was found between degree of anemia and HIV serostats among the study women with anemia.

Anemia had a significant association $(\mathrm{p}<0.05)$ with age, hookworm infestation, chronic illness and parity. This is because most illiterate mothers are did not know how to use family planning, from where family planning service given and some of them may think family planning method as harm full. Thus will have more blood loss during delivery and there will be no time to restore already depleted iron stores and hence anemia results.

\section{Conclusion}

Result of this study showed that the occurrence of anemia in pregnancy has been present in large proportion of pregnant women. The rate of anemia being higher among grand multi para in third trimester of pregnancy, in mothers who had chronic illnesses, mothers whose age above five. For pregnant women anemia can result in severe 
morbidity and reduces the resistance of blood loss with the result that death may result from the blood loss associated with normal delivery.

\section{Acknowledgment}

Above all; I would like to thanks God who gave me health. My heartfelt gratitude also goes to my friends for their guidance, support and encouragement through the course of my research. I am also grateful to Jimma University student research program for giving me this opportunity.

\section{Competing interest}

The authors declare that they have no competing interests.

\section{References}

1. CDC; 2010.pedatric and pregnancy Nutrition surveillance.
2. $\mathrm{WHO} / \mathrm{CDC}$ worldwide prevalence
of anemia
1993-2005:WHO
Database, WHO Press,Geneva,Switzerland,2008

3. Balarajan,U.Ramakrishana,E.Ozaltian, A.H.Shankarand S.V.Subramanian "anemia in low income and middle income countries "The lancet,vol.378,no9809 pp 2123-2135, 2011

4. Belachew T, Legesse Y. Risk factors for Anemia among pregnant women attending ANC at JUSH, south western Ethiopia. Ethio-Med-J2006Jul, 44(3):211-20

5. Christensen, RD. and Ohls, RK. Anaemias Unique to Pregnancy and the Prenatal Period.in: N.J,Rodgers,G.M., Paraskeyas.F.and Glader,B., Wintrobe clinical Hematology.Vol.2,11th Edition, Lippincott Williams and Wilkins,USA,1467-1486

6. Central Statistical Agency [Ethiopia], ICF International. 2012. Ethiopia Demographic and Health Survey 2011. Addis Ababa, Ethiopia and Calverton, Maryland, USA: Central Statistical Agency and ICF International 2012.

7. Johan W.ADMESON/Dan L.Lang S 1998 Anemia In Harrison principle of medicine 14 edition.

8. Harton JJ Ras.2003. The economics of deficiency available bank bray resource Journals . food policy,28:5175

9. Eyasu Ejeta,Birhan Alemnew,Ashetu Fikadu,Fikadu,Merga Fikadu,Lensa Tesfaye; Prevalence of anemia and risk factors among pregnant mothers; Nekemt Referral hospital, south west ethiopia,2014 .Http://www.iiste.org/book/.

10. Massawe SN, Urassa En, NystromL, Lind markG; 1999: Effectiveness of primary level care in decreasing anemia at term in Tanzania. Acta Obstet Gynecol scand; 78:573-579.

11. EO Uche-NWachi, Odekumle, Jacinto singh. Anemia in pregnancy: Association with parity Abortions ,and chilled spacing in Uganda.Afr Health sci.; 2010,10:66-70

12. Cyrilc, E. Onah .Prevalence of anemia among pregnant women. Med Gen med, 2007.9:251-8. 
Table 1: background characteristics of attendants at ANC follow up clinic of JUSH, 2018

\begin{tabular}{|c|c|c|c|}
\hline \multirow[t]{2}{*}{ Variables } & \multirow[t]{2}{*}{ Categories } & \multicolumn{2}{|c|}{ Frequency } \\
\hline & & Number & Percentage \\
\hline \multirow[t]{4}{*}{ Age } & $<18$ & 7 & 3.4 \\
\hline & $18-25$ & 105 & 50.7 \\
\hline & $26-35$ & 88 & 42.5 \\
\hline & $>35$ & 7 & 3.4 \\
\hline \multirow[t]{3}{*}{ Trimester } & $1 \mathrm{st}$ & 46 & 22.2 \\
\hline & $2 \mathrm{nd}$ & 75 & 36.2 \\
\hline & $3 r d$ & 88 & 41.5 \\
\hline \multirow[t]{4}{*}{ Parity } & 0 & 62 & 30 \\
\hline & $1-2$ & 91 & 44 \\
\hline & $3-5$ & 46 & 22.2 \\
\hline & $>5$ & 8 & 3.9 \\
\hline \multirow[t]{2}{*}{ Residence } & Urban & 124 & 59.9 \\
\hline & Rural & 83 & 40.1 \\
\hline \multirow[t]{3}{*}{ Literacy } & Illiterate & 77 & 37.2 \\
\hline & Primary & 46 & 22.2 \\
\hline & Secondary school \& above & 84 & 40.6 \\
\hline \multirow[t]{4}{*}{ Ethnicity } & Oromo & 146 & 70.5 \\
\hline & Amhara & 40 & 19.3 \\
\hline & Tigre & 16 & 7.7 \\
\hline & Other & 5 & 2.4 \\
\hline \multirow[t]{4}{*}{ Religion } & Muslim & 112 & 54.2 \\
\hline & Orthodox & 63 & 30.4 \\
\hline & Protestant & 32 & 15.5 \\
\hline & Other & 0 & 0 \\
\hline \multirow[t]{3}{*}{ Income monthly } & $<1000$ birr & 159 & 76.8 \\
\hline & 1000-200birr & 44 & 21.3 \\
\hline & $>2000$ birr & 4 & 1.9 \\
\hline \multirow[t]{2}{*}{ Birth interval } & $<2 \mathrm{yr}$ & 164 & 78.3 \\
\hline & $>=2 \mathrm{yr}$ & 43 & 21.7 \\
\hline \multirow[t]{2}{*}{ Abortion } & Yes & 65 & 31.4 \\
\hline & No & 142 & 68.6 \\
\hline \multirow[t]{2}{*}{ Contraceptive use } & Yes & 105 & 50.7 \\
\hline & No & 102 & 49.3 \\
\hline \multirow[t]{2}{*}{ Chronic illness } & Yes & 50 & 24.2 \\
\hline & No & 157 & 75.8 \\
\hline \multirow[t]{2}{*}{ Anemia } & Yes & 65 & 31.4 \\
\hline & No & 142 & 68.6 \\
\hline
\end{tabular}


Table 2: Risk factors associated with anemia among pregnant women attending ANC clinic at JUSH, 2018

\begin{tabular}{|c|c|c|c|c|c|c|}
\hline \multirow[t]{3}{*}{ Variables } & \multirow[t]{3}{*}{ Categories } & \multicolumn{4}{|c|}{ Anemia } & \multirow[t]{3}{*}{ P-Value } \\
\hline & & \multicolumn{2}{|l|}{ yes } & \multicolumn{2}{|l|}{ No } & \\
\hline & & No. & $\%$ & No. & $\%$ & \\
\hline \multirow[t]{4}{*}{ Age } & $<18 \mathrm{yr}$ & 1 & 14.2 & 6 & 85.9 & \multirow[t]{4}{*}{0.031} \\
\hline & $18-25 \mathrm{yr}$ & 27 & 25.7 & 78 & 74.3 & \\
\hline & $26-35 \mathrm{yr}$ & 32 & 36.3 & 56 & 63.7 & \\
\hline & $>35 \mathrm{yr}$ & 5 & 71.4 & 2 & 29.6 & \\
\hline \multirow[t]{3}{*}{ Trimester } & $1^{\text {st }}$ & 11 & 24 & 35 & 76 & \multirow[t]{3}{*}{0.245} \\
\hline & $2^{\text {nd }}$ & 23 & 30.6 & 52 & 69.4 & \\
\hline & $3^{\text {rd }}$ & 31 & 36 & 55 & 64 & \\
\hline \multirow[t]{4}{*}{ Parity } & 0 & 13 & 21 & 49 & 79 & \multirow[t]{4}{*}{0.032} \\
\hline & $1-2$ & 28 & 31 & 63 & 69 & \\
\hline & $3-5$ & 19 & 41.3 & 27 & 59.7 & \\
\hline & $>5$ & 5 & 62.5 & 2 & 37.5 & \\
\hline \multirow[t]{2}{*}{ Residency } & Urban & 35 & 28 & 89 & 72 & \multirow[t]{2}{*}{0.229} \\
\hline & Rural & 30 & 36 & 53 & 64 & \\
\hline \multirow[t]{3}{*}{ Literacy status } & Illiterate & 27 & 35 & 50 & 65 & \multirow[t]{3}{*}{0.061} \\
\hline & Primary school & 19 & 41.3 & 27 & 59.7 & \\
\hline & Secondary\&above & 19 & 22.6 & 65 & 77.4 & \\
\hline \multirow[t]{4}{*}{ Ethnicity } & Oromo & 41 & 28.1 & 105 & 71.9 & \multirow[t]{4}{*}{0.075} \\
\hline & Amhara & 16 & 40 & 24 & 60 & \\
\hline & Tigri & 8 & 50 & 8 & 50 & \\
\hline & Other & 0 & 0 & 5 & 100 & \\
\hline \multirow[t]{3}{*}{ Religion } & Muslim & 34 & 30.4 & 78 & 69.6 & \multirow[t]{3}{*}{0.749} \\
\hline & Orthodox & 22 & 35 & 41 & 65 & \\
\hline & Protestant & 9 & 28.1 & 23 & 71.9 & \\
\hline \multirow[t]{3}{*}{ Income } & $<1000$ birr & 51 & 32.1 & 108 & 67.9 & \multirow[t]{3}{*}{0.395} \\
\hline & $1000-2000$ birr & 14 & 31.8 & 30 & 68.2 & \\
\hline & $>2000$ birr & 0 & 0 & 4 & 100 & \\
\hline \multirow[t]{2}{*}{ Birth interval } & $<2 \mathrm{yr}$ & 51 & 31.5 & 111 & 68.5 & \multirow[t]{2}{*}{0.96} \\
\hline & $>2 \mathrm{yr}$ & 14 & 31.1 & 31 & 68.9 & \\
\hline \multirow[t]{2}{*}{ Abortion } & Yes & 26 & 40 & 39 & 60 & 0.071 \\
\hline & No & 39 & 27.5 & 103 & 72.5 & \\
\hline Contraceptive use & Yes & 27 & 25.7 & 78 & 74.3 & 0.071 \\
\hline & No & 38 & 37.2 & 64 & 62.8 & \\
\hline Chronic illness & Yes & 24 & 48 & 26 & 52 & 0.004 \\
\hline & No & 41 & 26.1 & 116 & 73.9 & \\
\hline Intestinal parasite & Yes & 13 & 39.4 & 20 & 60.6 & 0.281 \\
\hline & No & 52 & 29.9 & 122 & 70.1 & \\
\hline Malaria & Yes & 25 & 36.8 & 43 & 60.2 & 0.245 \\
\hline & No & 40 & 28.8 & 99 & 70.2 & \\
\hline
\end{tabular}




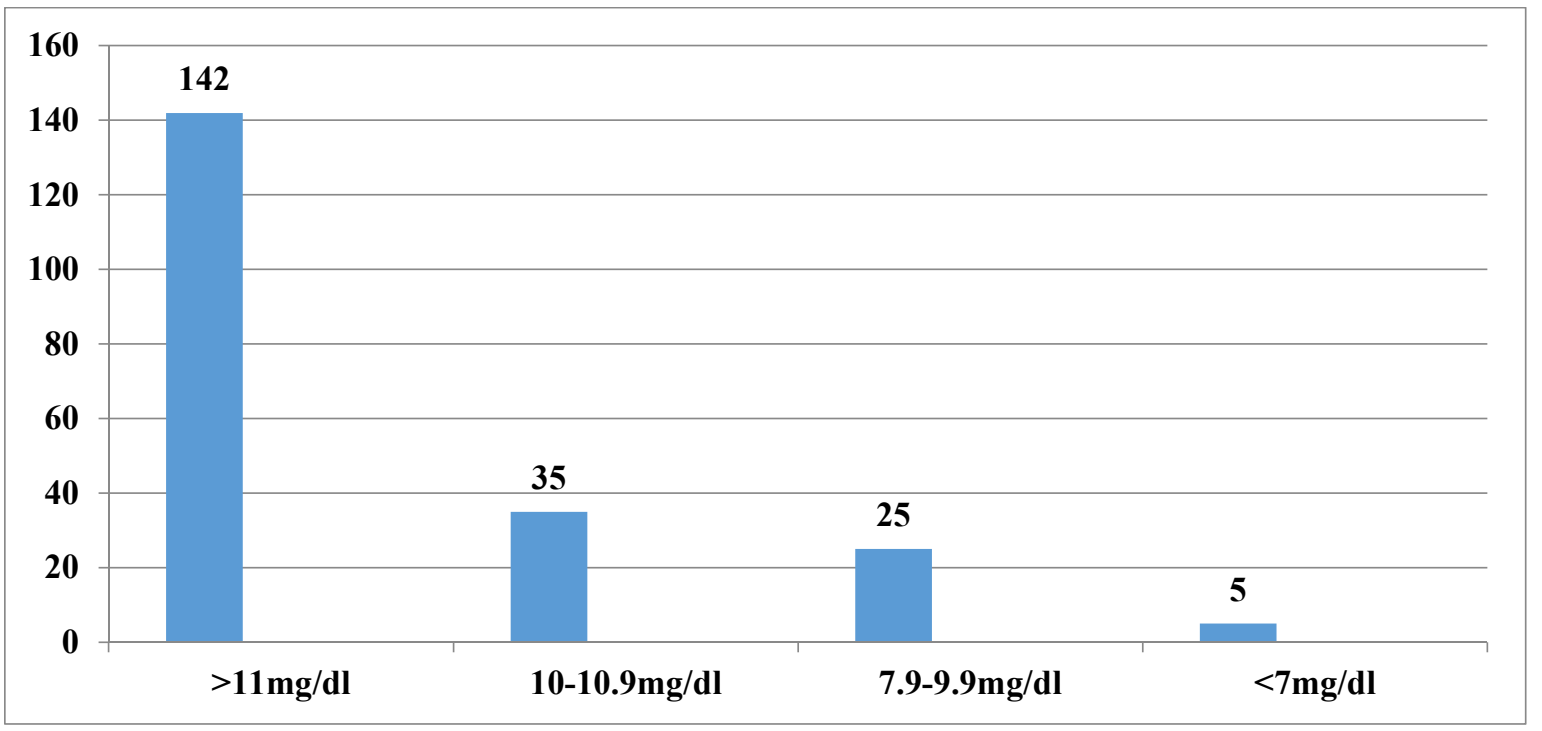

Graph 1: Severity of anemia among antenatal care attendants in Jimma University Specialized Hospital, 2018 G.C 